\title{
A Comparison of the Deterioration Characteristics in Verbal Fluency between Amnestic Mild Cognitive Impairment and Vascular Mild Cognitive Impairment
}

\author{
Haeyoon Kim, Yeonwook Kang, ${ }^{\mathrm{a}, \mathrm{b}}$, Kyung-Ho Yu ${ }^{\mathrm{b}}$, Byung-Chul Lee ${ }^{\mathrm{b}}$ \\ ${ }^{a}$ Department of Psychology, Hallym University, Chuncheon, Korea \\ ${ }^{b}$ Department of Neurology, Hallym University Sacred Heart Hospital, Anyang, Korea
}

Correspondence: Yeonwook Kang, PhD Department of Psychology, Hallym University, 1 Hallymdaehak-gil, Chuncheon 24252, Korea Tel: +82-33-248-1724

Fax: +82-33-256-3424

E-mail: ykang@hallym.ac.kr

Received: October 5, 2015

Revised: November 22, 2015

Accepted: November 30, 2015

This work was supported by Hallym University Specialization Fund (HRF-S-21)

\begin{abstract}
Objectives: The present study was conducted to examine when verbal fluency is decreased in amnestic multi-domain mild cognitive impairment $(\mathrm{MCl})$ and vascular $\mathrm{MCl}$, and to compare the deterioration characteristics in verbal fluency between amnestic multi-domain $\mathrm{MCl}$ and vascular $\mathrm{MCl}$. Methods: The subjects were 34 normal elderly, 36 with dementia of the Alzheimer type, 39 with vascular dementia, 72 with amnestic multi-domain $\mathrm{MCl}$, and 70 with vascular $\mathrm{MCl}$. The $\mathrm{MCl}$ groups were classified into two subgroups, early $\mathrm{MCl}(0.5-$ 2.0) and late MCI (2.5-4.0), based on the Clinical Dementia Rating-Sum of Boxes. The subjects were given semantic (animal) and phonemic ( $\neg, 0$, , ᄉ) fluency tests. Results: In amnestic multi-domain $\mathrm{MCl}$, semantic fluency showed progressive deterioration from the early amnestic multi-domain $\mathrm{MCl}$ to early dementia of the Alzheimer's type, whereas in vascular MCl it was significantly decreased in the late vascular $\mathrm{MCl}$ but maintained in early vascular dementia. In vascular $\mathrm{MCl}$, phonemic fluency had progressive deterioration from the early vascular $\mathrm{MCl}$ to early vascular dementia, whereas in amnestic multi-domain $\mathrm{MCl}$ it was significantly decreased in the early amnestic multi-domain $\mathrm{MCl}$ and maintained in early dementia of the Alzheimer's type. Conclusion: These results suggest that the deterioration characteristics of semantic and phonemic fluency are different between amnestic multi-domain $\mathrm{MCl}$ and vascular $\mathrm{MCl}$.
\end{abstract}

Keywords: Verbal fluency, Semantic fluency, Phonemic fluency, Mild cognitive impairment, Amnestic mild cognitive impairment, Vascular mild cognitive impairment
구어 유창성(verbal fluency)은 기존에 저장되어 있던 어휘집(lexicon)과 의미기억(semantic memory)으로부터 정보를 전략적으로 탐색하고 인출하는 능력을 의미한다(Sauzéon, Lestage, Raboutet, N'Kaoua, \& Claverie, 2004). 임상장면에서 구어 유창성은 통제단 어연상검사(Controlled Oral Word Association Test, COWAT; Lucas et al., 1998)로 평가되는데 COWAT는 제한된 시간(보통은 1분) 내에 특정 범주(예: 동물, 가게물건, 채소 등)에 속하는 단어를 생성 하는 “의미 유창성(semantic fluency)" 검사와 특정 음소(예: F·A·S, C.F.L, ᄀ. ․스)로 시작되는 단어를 생성하는 "음소 유창성(phone- mic fluency)" 검사로 구성되어 있다. 의미 유창성 검사와 음소 유 창성 검사는 둘 다 전두엽 기능과 의미기억을 평가하는 중요한 검 사로 인정되어 왔다(Lezak, Howieson, Bigler, \& Tranel, 2012). 그러 나 의미 유창성 검사의 결과는 전두엽과 측두엽 영역의 기능 손상 을 모두 민감하게 예측한 반면 음소 유창성 검사의 결과는 전두엽 영역의 기능 손상을 보다 민감하게 예측하였다는 연구 결과가 보 고됨(Henry \& Crawford, 2004)에 따라서 두 검사의 수행결과를 구 분하여 분석해야 한다는 의견들이 대두되었다.

치매환자들이 정상 노인에 비해서 구어 유창성이 유의하게 저하 
되므로 구어 유창성의 저하가 치매 변별에 유용한 지표가 될 수 있 다는 사실이 밝혀진 후(Solomon et al., 1998), COWAT는 치매를 평가하는 신경심리학적 평가도구에 반드시 포함되는 중요한 검사 가 되었고 다양한 치매 환자들을 대상으로 한 구어 유창성 연구가 많이 수행되었다. 연구 결과, 가장 대표적인 치매인 알츠하이머형 치매(dementia of the Alzheimer's type, DAT)는 병의 초기부터 의 미 유창성이 감소하는 것으로 밝혀졌다(Heinzel et al., 2013; Henry, MacLeod, Phillips, \& Crawford, 2004). 그러나 음소 유창성의 경우에는 초창기에 수행된 연구(Butters, Granholm, Salmon, Grant, \& Wolfe, 1987)들은 초기 단계의 DAT가 정상집단과 유의미한 차 이를 보이지 않는다는 결과를 보고하였으나, 많은 후속 연구들에 서는 DAT가 초기에도 음소 유창성이 저하되는 것으로 밝혀졌다 (Henry et al., 2004; Jones, Laukka, \& Bäckman, 2006; Pakhomov \& Hemmy, 2014; Park et al., 2006). DAT뿐만 아니라 전반적인 전두 엽 기능의 장애를 특징적으로 나타내는 혈관 치매(vascular dementia, $\mathrm{VaD}$ )도 구어 유창성의 저하를 보인다(Garrett et al., 2004). 의미 유창성도 정상 노인들보다 저하되지만(Jones et al., 2006) 특 히 음소 유창성은 혈관치매의 초기 단계부터 저하된다고 보고되었 다(Fahlander, Wahlin, Almkvist, \& Bäckman, 2002; Hart \& Best, 2014).

구어 유창성의 저하는 치매의 이전 단계로 간주되고 있는 경도인 지장애(mild cognitive impairment, MCI)에서도 나타난다. MCI는 (1) 주관적으로 인지기능의 저하를 경험하고, (2) 객관적인 신경심 리검사에서도 정상범주 이하의 수행을 보이지만, (3) 일상생활기능 을 그대로 유지하고 있어서 치매가 아닌 상태를 의미한다(Petersen, 2004). MCI는 저하된 인지기능의 종류와 발병 기전에 따라 다 양한 유형으로 분류되는데, 그 중에서 기억력과 함께 1 개 이상의 다른 인지영역이 저하된 다영역 기억성 경도인지장애(amnestic multi-domain mild cognitive impairment, amMCI)는 DAT로 진 행될 가능성이 가장 높은 집단으로 알려져 있다(Alexopoulos, Grimmer, Perneczky, Domes, \& Kurz, 2006). amMCI 중 매년 약 $10 \%-15 \%$ 가 DAT로 진행되었고(Petersen et al., 1999, 2001), 2년 후 에는 $41 \%$ (Hsiung et al., 2006), 6년 후에는 80\%가 DAT로 진행되었 다는 연구(Petersen et al., 1999, 2001)들이 보고되었다. amMCI도 이미 정상집단에 비해서 의미 유창성이 저하되어 있다는 연구결과 들이 보고되었으나(Gainotti, Quaranta, Vita, \& Marra, 2014; Murphy, Rich, \& Troyer, 2006), 음소 유창성은 amMCI에서 비교적 유 지된다는 연구(Jones et al., 2006)와 음소 유창성도 정상집단에 비 해서 저하된다(Murphy et al., 2006)는 서로 상반된 연구결과가 보 고되었다.
혈관성 경도인지장애(vascular mild cognitive impairment, VaMCI; Gorelick et al., 2011)는 혈관질환으로 인해서 인지기능이 저하 된 MCI로 인지영역들 중에서 특히 전두엽 기능의 저하를 특징적으 로 보이지만 일상생활기능은 잘 유지하고 있는 환자들이다. VaMCI 도 역시 $\mathrm{VaD}$ 로 진행될 가능성이 높은 집단으로 알려져 있는데, 종 단 연구들의 결과에 따르면 $\mathrm{VaMCI}$ 환자들 중 $11 \%$ 가 1 년 후에 $\mathrm{VaD}$ 로 진행되었고(Tham et al., 2002), 5년 후에는 약 $46 \%$ 가 $\mathrm{VaD}$ 로 진 행되었다고 한다(Wentzel et al., 2001). 이러한 VaMCI 환자들은 구 어 유창성 수행에 있어서, 정상집단에 비해 음소 유창성은 저하되 었으나 의미 유창성은 유지되고 있다는 연구 결과(Garrett et al., 2004)도 있고, $\mathrm{VaMCI}$ 가 정상집단보다 음소 유창성과 의미 유창성 이 모두 저하되었음을 보고한 연구들도 있다(Hart \& Best, 2014; Kwon, 2012).

이제까지 살펴본 바와 같이 선행연구들은 $\mathrm{MCI}$ 집단, 즉 $\mathrm{amMCI}$ 와 $\mathrm{VaMCI}$ 의 의미유창성과 음소유창성의 결함에 대해서 다소 일 관되지 못한 결과들을 보고하였다. 그 이유는 아마도 최근의 연구 들(O’Bryant et al., 2008, 2010)에서 지적된 바와 같이 MCI 진단기 준 자체의 문제로 인해서 $\mathrm{MCI}$ 집단에 매우 경한 인지기능 저하를 지닌 환자부터 “초기” 치매단계라고 부를 수 있을 정도의 환자까지 다양한 수준의 환자들이 포함되었기 때문인 것으로 생각된다. 따 라서 본 연구는 O’Bryant 등(2008)이 치매임상평가척도(Clinical Dementia Rating, CDR)의 박스총점(CDR-Sum of boxes, CDR$\mathrm{SB})$ 을 기준으로 제안한 절단점수를 사용하여 $\mathrm{amMCI}$ 와 $\mathrm{VaMCI}$ 를 초기와 후기 단계로 더 세분화하고, 세분화된 집단들의 의미 유 창성과 음소 유창성 검사수행을 정상집단 및 치매집단과 비교함으 로써 $\mathrm{amMCI}$ 와 $\mathrm{VaMCI}$ 의 구어 유창성 저하 양상을 더 정확하게 밝히기 위해서 수행되었다.

\section{연구 방법}

\section{연구대상}

정상노인 34 명, $\mathrm{MCI}$ 환자 142 명, 초기 $\mathrm{DAT}$ 환자 36 명 및 초기 $\mathrm{VaD}$ 환자 39 명이 참여하였다. 정상노인은 건강 선별 기준(Christensen, Multhaup, Nordstrom, \& Voss, 1991)에 부합하고 한국형 간이정신상태검사(Korean Mini-Mental State Examination, KMMSE; Kang, 2006)에서 16\%ile 이상의 수행을 보인 노인들이었다.

$\mathrm{MCI}$ 환자들 중 72 명은 일상생활기능의 유의한 장애를 보이지는 않았으나 기억력의 저하와 함께 주의집중능력, 언어능력, 시공간기 능, 전두엽 기능 등의 인지기능들 중 한 가지 이상의 인지기능 저하 를 보인 amMCI 환자였고, 70 명은 뇌졸중 발병 3 개월 후에 평가된 
신경심리학적 검사 결과, 인지기능의 저하를 보이지만 일상생활기 능의 장애가 없는 VaMCI 환자였다. $\mathrm{MCI}$ 환자들을 다시 $\mathrm{CDR}-\mathrm{SB}$ 점수가.5-2.0에 속하는 초기(early) MCI (E-MCI) 집단과 2.5-4.0에 속하는 후기(late) MCI (L-MCI) 집단으로 분류하였다. 그 결과 amMCI 집단은 E-amMCI 41명과 L-amMCI 31명으로 분류되었고 VaMCI 집단은 E-VaMCI 39명과 L-VaMCI 31명으로 분류되었다.

환자 집단은 대학병원 신경과에 내원한 환자들 중에서 신경과 전문의의 임상적 소견과 종합적인 신경심리검사 및 뇌영상검사 결 과에 근거하여 치매로 진단된 환자들로서, $\mathrm{CDR}$ 총점(CDR-Global score, CDR-GS)으로 평가된 치매 심각도가 1.0에 해당되는 초기 $\mathrm{DAT}$ 또는 초기 $\mathrm{VaD}$ 였다. $\mathrm{DAT}$ 와 $\mathrm{VaD}$ 는 각각 NINCDS-ADRDA (McKhann et al., 1984)의 "probable Alzheimer's disease"와 NINDSAIREN (Román et al., 1993)의 "probable vascular dementia" 진단 기준에 근거하여 진단된 환자들이었다.

\section{검사 도구 및 절차}

정상노인 집단에 속하는 대상자를 선별하기 위하여, 인지장애와 관련된 다양한 질환들(예: 뇌졸중, 당뇨, 고혈압, 외상성 뇌손상, 간 질 등)의 병력이 있는지를 확인하는 Christensen 등(1991)의 건강 선별 설문지와 전반적인 인지기능 수준을 평가하는 K-MMSE를 실 시하였다.

선정된 모든 연구 대상자들에게 동물 범주에 대한 의미 유창성 검사와 ㄱ, O, 세에 대한 음소 유창성 검사(Kang, Jang, \& Na, 2012) 를 개인검사로 실시하였다. 유창성 검사는 의미 유창성 검사를 먼 저 실시하고 난 다음에 음소 유창성 검사를 실시하였고 COWAT (Lucas et al., 1998)의 실시방법을 적용하여 각 시행 당 1 분간 반응 하도록 하였으며 모든 반응을 순서대로 반응기록지에 그대로 기록 하였다. 반복반응, 동물범주에 속하지 않거나 주어진 음소로 시작 하지 않은 오반응 및 고유명사는 점수에서 제외하였고 파생어(예: 온다.오고·오니·오시오)는 첫 반응에만 점수를 주었다. 한글사전 (http://stdweb2.korean.go.kr.html)에 수록된 사투리와 자주 사용 되는 외국어나 외래어는 정답으로 간주하였다. 동물 범주 유창성 검사에서 상위 개념(예: 새)과 하위 개념(예: 독수리, 종달새, 낑)의 단어를 함께 반응한 경우에는 상위개념의 단어는 점수에서 제외시 키고 하위개념의 단어에만 점수를 주었다.

\section{자료분석}

집단 간 인구학적 특성의 차이를 확인하기 위하여 일변량 분석 (ANOVA)을 실시하였고, 집단 간 차이가 발견된 나이와 성별을 공 변인(covariate)으로 통제하고 의미 유창성 점수와 음소 유창성 점
수에 대해 각각 일변량 공분산분석(ANCOVA)을 실시하였다. 집 단 간의 구체적인 차이를 확인하기 위해 Bonferroni 조정 후 사후 검증을 시행하였다. 모든 통계적 분석은 SPSS PC 21.0을 사용하여 수행되었다.

\section{연구 결과}

\section{연구 대상의 인구학적 특성, $\mathrm{K}-\mathrm{MMSE}$ 및 $\mathrm{CDR}$}

정상노인, E-amMCI, L-amMCI, E-VaMCI, L-VaMCI, 초기 $\mathrm{DAT}$ 및 초기 $\mathrm{VaD}$, 전체 7개 집단의 인구학적 변인들, 즉 나이, 성 별, 교육연수의 차이 여부를 확인하기 위하여 일변량 분산분석 (ANOVA)과 $\chi^{2}$ 검증을 실시하였다(Table 1). 그 결과 교육연수에 있 어서는 집단 차이가 발견되지 않았으나 $\left(F_{(6,242)}=1.66, n s\right)$, 나이 $\left(F_{(6,242)}=3.98, p<.01\right)$ 와 성별 $\left(\chi^{2}=17.73, p<.01\right)$ 에 있어서 집단 간 차이가 발견되었다. 따라서 의미 유창성과 음소 유창성의 집단 간 차이를 확인하기 위한 모든 통계분석은 나이와 성별을 통제한 후 실시되었다.

K-MMSE 총점 $\left(F_{(6,242)}=42.65, p<.001\right), \mathrm{CDR}-\mathrm{GS}\left(F_{(6,242)}=727.81\right.$, $p<.001)$ 및 $\mathrm{CDR}-\mathrm{SB}\left(F_{(6,242)}=378.57, p<.001\right)$ 에 있어서도 집단 간 유의미한 차이가 있음이 확인되었다. 사후분석 결과, K-MMSE 총 점에 있어서는 정상집단, 초기 $\mathrm{MCI}$, 후기 $\mathrm{MCI}$ 및 치매집단 간에 각 각 서로 유의한 차이가 있음이 확인되었다. 그러나 초기 $\mathrm{MCI}$ 두 집 단(E-amMCI와 E-VaMCI), 후기 $\mathrm{MCI}$ 두 집단(L-amMCI와 L-Va$\mathrm{MCI}$ ) 및 두 치매집단(초기 DAT와 초기 $\mathrm{VaD}$ ) 간의 K-MMSE 총점 의 차이는 발견되지 않았다. 전반적인 치매의 심각도를 나타내는 척도인 CDR-GS에 있어서는 MCI 집단과 치매집단 간의 차이만 발 견되었고 초기와 후기 $\mathrm{MCI}$ 집단 간의 차이와 초기 $\mathrm{DAT}$ 와 $\mathrm{VaD}$ 간 의 차이는 발견되지 않았다. 그러나 CDR-SB에 있어서는 초기와 후 기 $\mathrm{MCI}$ 간의 차이만 발견되었고, 같은 시기에 속한 $\mathrm{amMCI}$ 와 $\mathrm{Va}-$ $\mathrm{MCI}$ 의 차이는 발견되지 않았다. 이 결과는 본 연구에 참여한 " $\mathrm{E}$ amMCI와 E-VaMCI," "L-amMCI와 L-VaMCI," “초기 DAT와 초 기 $\mathrm{VaD}$ ” 각각의 두 집단들의 전반적인 치매심각도 수준이 서로 차 이가 없음을 시사한다.

\section{의미 유창성}

의미 유창성에 있어 집단 간 유의한 차이가 발견되었다 $\left(F_{(6,242)}=\right.$ $21.31, p<.001$ ) (Table 2). 사후분석 결과, 정상집단과 초기 DAT 간 의 유의한 수행차이가 발견되었다 $(t=7.40, p<.001) . \mathrm{E}-\mathrm{amMCI}$ 는 정상집단이나 L-amMCI와는 차이를 나타내지 않았으나초기 DAT 보다는 유의하게 우수한 수행을 나타냈다 $(t=4.75, p<.001)$. 반면, 
Table 1. Subjects' demographic characteristics, K-MMSE, CDR-GS, and CDR-SB

\begin{tabular}{|c|c|c|c|c|c|c|c|c|c|}
\hline & $\mathrm{NE}(\mathrm{a})$ & E-amMCI (b) & E-VaMCI (c) & L-amMCl (d) & L-VaMCI (e) & DAT (f) & $\operatorname{VaD}(g)$ & For $\chi^{2}$ & Post-hoc (Bonferroni) \\
\hline No. of subjects & 34 & 41 & 39 & 31 & 31 & 36 & 39 & & \\
\hline Age (yr) & 72.62 (6.05) & 69.93 (10.07) & $67.05(8.86)$ & 73.97 (6.99) & 69.94 (9.39) & $73.50(7.74)$ & $73.92(6.10)$ & $3.98^{* *}$ & $\begin{array}{c}a=b=d=e=f=g, \\
d=f=g>c, a=b=c=e\end{array}$ \\
\hline Sex (M:F) & 10:24 & 19:22 & $24: 15$ & $9: 22$ & $17: 14$ & $9: 27$ & $14: 25$ & $\chi^{2}=17.73^{* * *}$ & - \\
\hline Education (yr) & 10.06 (3.68) & $10.37(4.19)$ & $8.90(3.41)$ & 7.77(4.29) & $8.86(5.75)$ & $8.92(4.56)$ & $8.19(4.61)$ & 1.66 & - \\
\hline K-MMSE & $28.88(1.41)$ & $26.66(2.09)$ & $25.85(2.27)$ & $23.55(1.57)$ & $23.65(2.70)$ & $21.53(3.34)$ & $20.74(3.18)$ & $42.65^{* * *}$ & $a>b=c>d=e>f=g$ \\
\hline CDR-GS & $.00(.00)$ & $.50(.00)$ & $.50(.00)$ & $.53(.12)$ & $.55(.15)$ & $1.00(.00)$ & $1.00(.00)$ & $727.81^{* * *}$ & $\mathrm{a}<\mathrm{b}=\mathrm{c}=\mathrm{d}=\mathrm{e}<\mathrm{f}=\mathrm{g}$ \\
\hline CDR-SB & $.00(.00)$ & $1.23(.46)$ & $1.06(.53)$ & $3.00(.70)$ & $3.02(.54)$ & $4.85(.73)$ & $5.24(.92)$ & $378.57^{* * *}$ & $\mathrm{a}<\mathrm{b}=\mathrm{c}<\mathrm{d}=\mathrm{e}<\mathrm{f}=\mathrm{g}$ \\
\hline
\end{tabular}

Values are presented as mean (SD).

$\mathrm{NE}=$ normal elderly; $\mathrm{MCl}=$ mild cognitive impairment; $\mathrm{E}$-amMCl=early amnestic multi-domain $\mathrm{MCl} ; \mathrm{E}-\mathrm{VaMCl}=$ early vascular $\mathrm{MCl}$; L-amMCl=late amnestic multi-domain $\mathrm{MCl} ; \mathrm{L}-\mathrm{VaMCl}=$ late vascular MCl; DAT = dementia of the Alzheimer's type; VaD=vascular dementia; K-MMSE=Korean-Mini Mental State Examination; CDR-GS=Clinical Dementia Rating-Global score; CDR-SB=Clinical Dementia Rating-Sum of boxes.

${ }^{* *} p<.01,{ }^{* * *} p<.001$

Table 2. Group differences in semantic and phonemic fluency

\begin{tabular}{lccccccccc}
\hline & NE (a) & E-amMCl (b) & E-VaMCl (c) & L-amMCl (d) & L-VaMCl (e) & DAT (f) & VaD (g) & $F$ & Post-hoc (Bonferroni) \\
\hline No. of subjects & 34 & 41 & 39 & 31 & 31 & 36 & 39 & & \\
Semantic fluency & $14.56(3.48)$ & $12.54(3.70)$ & $12.77(2.62)$ & $10.90(2.76)$ & $9.13(3.18)$ & $9.03(3.18)$ & $7.85(2.61)$ & $21.31^{* * *}$ & $\begin{array}{c}a=b=c>e=f=g, \\
b=c=d>g, a>d=e=f\end{array}$ \\
Phonemic fluency & $27.76(8.06)$ & $21.51(9.37)$ & $17.90(9.08)$ & $17.97(7.53)$ & $12.52(7.57)$ & $15.89(8.19)$ & $9.44(6.22)$ & $\begin{array}{c}19.94^{* * *} \\
a>b=c=d=f>g, \\
b>e, c=d=e=f, e=g\end{array}$ \\
\hline
\end{tabular}

Values are presented as mean (SD).

$\mathrm{NE}=$ normal elderly; $\mathrm{MCl}=$ mild cognitive impairment; $\mathrm{E}-\mathrm{amMCl}=$ early amnestic multi-domain $\mathrm{MCl} ; \mathrm{E}-\mathrm{VaMCl}=$ early vascular $\mathrm{MCl} ; \mathrm{L}$-amMCl=late amnestic multi-domain $\mathrm{MCl} ; \mathrm{L}-\mathrm{VaMCl}=$ late vascular MCl; DAT = dementia of the Alzheimer's type; VaD = vascular dementia.

${ }^{* * *} p<.001$.

L-amMCI는 E-amMCI나 초기 DAT와는 수행차이를 나타내지 않 았으나 정상집단보다 유의하게 저하된 수행을 나타냈다 $(t=-4.69$, $p<.001)$.

$\mathrm{VaMCI}$ 의 경우에는 사후분석에서 정상집단과 E-VaMCI 간의 차이가 발견되지 않았다. $\mathrm{L}-\mathrm{VaMCI}$ 와 초기 $\mathrm{VaD}$ 의 차이도 발견되 지 않았으나 $\mathrm{L}-\mathrm{VaMCI}$ 는 정상집단과 $\mathrm{E}-\mathrm{VaMCI}$ 보다 유의하게 저하 된 수행을 나타내었고 $(t=-7.01, p<.001 ; t=-4.75, p<.001)$, 초기 $\mathrm{VaD}$ 도 정상집단과 $\mathrm{E}-\mathrm{VaMCI}$ 보다 유의하게 저하된 수행을 나타냈 다 $(t=-9.15, p<.001 ; t=-6.50, p<.001)$.

또한, $\mathrm{amMCI}$ 와 $\mathrm{VaMCI}$ 간의 의미 유창성의 차이는 초기와 후 기에서 모두 발견되지 않았고, 초기 DAT와 초기 $\mathrm{VaD}$ 의 의미 유창 성 차이도 발견되지 않았다. 그러나 L-VaMCI는 초기 DAT와 차이 를 나타내지 않은 반면 L-amMCI는 초기 $\mathrm{VaD}$ 보다 우수한 수행을 보였다 $(t=4.08, p<.01)$.

\section{음소 유창성}

음소 유창성에 있어서도 집단 간 유의한 차이가 발견되었다 $\left(F_{(6,242)}=19.94, p<.001\right)$ (Table 2). 사후 분석 결과, amMCI는 초기
부터 정상집단과 유의한 차이를 나타냈으나 $(t=-3.69, p<.01) \mathrm{E}-$ $\mathrm{amMCI}, \mathrm{L}-\mathrm{amMCI}$ 및 초기 DAT 간에서는 유의미한 차이가 발견 되지 않았다.

반면 $\mathrm{VaMCI}$ 의 경우에는 $\mathrm{E}-\mathrm{VaMCI}$ 와 L-VaMCI 간의 차이는 발 견되지 않았으나 $\mathrm{E}-\mathrm{VaMCI}$ 가 정상집단 및 초기 $\mathrm{VaD}$ 와 차이를 나 타내었다 $(t=-5.75, p<.001 ; t=3.76, p<.01) . \mathrm{L}-\mathrm{VaMCI}$ 는 정상집단 과는 차이를 나타냈으나 $(t=-7.99, p<.001)$ 초기 $\mathrm{VaD}$ 와는 차이를 보이지 않았다.

의미 유창성의 결과와 마찬가지로 $\mathrm{amMCI}$ 와 $\mathrm{VaMCI}$ 간의 음소 유창성 차이는 초기와 후기에서 모두 발견되지 않았다. 반면 초기 $\mathrm{VaD}$ 가 초기 $\mathrm{DAT}$ 보다 유의하게 저하된 음소 유창성을 나타냈고 ( $t=-3.58, p<.01), \mathrm{E}-\mathrm{VaMCI}$ 는 후기 $\mathrm{MCI}(\mathrm{L}-\mathrm{amMCI} \& \mathrm{~L}-\mathrm{VaMCI})$ 및 초기 DAT와 동일한 수행 수준을 보였다.

\section{논의 및 결론}

본 연구는 전두엽 기능과 치매 선별의 중요한 지표로 사용되어 온 구어 유창성이 경도인지장애 수준에서 언제 어떻게 저하되는지를 
밝히고 그 저하 양상이 의미 유창성과 음소 유창성에 있어서 차이 가 있는지를 확인하기 위해서 수행되었다. 다양한 수준의 인지장애 를 지닌 MCI들을 한 집단에 포함함으로써, 비일관적인 결과를 산 출한 선행연구들의 문제점을 보완하기 위해서 기억성 경도인지장 애( $\mathrm{amMCI})$ 와 혈관성 경도인지장애(VaMCI) 환자들을 $\mathrm{CDR}-\mathrm{SB}$ 점 수 2.0 을 기준으로 분류하였다. 그 결과 두 $\mathrm{MCI}$ 집단은 초기 $\mathrm{MCI}$ 집단(.5-2.0)과 후기 $\mathrm{MCI}$ 집단(2.5-4.0)으로 나뉘었고, 각 $\mathrm{MCI}$ 집단 의 구어 유창성을 정상집단 및 초기 치매집단과 비교하였다.

연구 결과, 의미 유창성은 $\mathrm{amMCI}$ 집단에서는 $\mathrm{MCI}$ 초기부터 초 기 DAT에 이르기까지 점진적으로 저하되는 양상을 나타낸 반면, $\mathrm{VaMCI}$ 의 경우에는 $\mathrm{MCI}$ 후기에 이르러서야 정상집단과의 차이를 나타내었고 L-VaMCI의 수준은 초기 $\mathrm{VaD}$ 까지 유지되었으며 L$\mathrm{VaMCI}$ 의 수준은 초기 DAT와도 차이를 나타내지 않았다. 이러한 결과는 $\mathrm{amMCI}$ 가 $\mathrm{MCI}$ 초기 단계부터 의미 유창성이 저하되지만 $\mathrm{VaMCI}$ 는 그보다 다소 늦은 $\mathrm{MCI}$ 후기 단계가 되어야 의미 유창성 이 저하된다는 사실을 시사한다.

의미 유창성이 저하되는 것은 의미기억을 담당하는 뇌 영역의 구조적인 손상에 기인한 것으로, 대상의 개념과 독특한 특징을 결 합하는 능력이 저하되거나 상실되어 나타난다(Chertkow \& Bub, 1990). 알츠하이머병은 베타 아밀로이드 단백질(beta amyloid protein)이라는 독성물질이 해마가 위치한 내측 측두엽에서부터 시작 하여 외측 측두엽, 두정엽 및 전두엽의 순으로 뇌 전반에 쌓여서 뇌 신경세포의 손상을 일으키게 되는 질환으로 알려져 있다(Cummings, Vinters, Cole, \& Khachaturian, 1998). 따라서 DAT의 경우 초기부터 측두엽과 관련된 의미기억의 손상을 나타내게 된다(Keilp, Gorlyn, Alexander, Stern, \& Prohovnik, 1999). 그러나 DAT의 전 구단계로 알려진 amMCI에서도 이미 측두엽의 손상이 발견되었고 (Petersen et al., 2006) 의미 유창성을 포함하여 의미기억과 관련된 과제들(예: 이름대기과제)에서 $\mathrm{amMCI}$ 가 정상인보다 저하된 수행 을 나타냈다는 연구결과가 보고된 바 있다(Adlam, Bozeat, Arnold, Watson, \& Hodges, 2006). 따라서 의미 유창성이 초기 amMCI에 서 이미 정상집단보다 유의하게 저하되었고 치매 단계로 진행하면 서 점차 계속 저하된다는 것을 보여준 본 연구의 결과는 선행연구 들과 일치하는 동시에 $\mathrm{MCI}$ 단계 중에서도 매우 일찍부터 저하된 다는 사실을 밝힌 점에서 중요한 발견이라고 생각한다.

반면 본 연구의 결과에 따르면 $\mathrm{VaMCI}$ 의 경우에는 $\mathrm{amMCI}$ 보다 는 조금 늦게 $\mathrm{VaMCI}$ 후기부터 의미 유창성이 저하되고 그 수준이 $\mathrm{VaD}$ 초기까지 유지되는 것으로 밝혀졌다. 이러한 차이는 $\mathrm{VaMCI}$ 와 $\mathrm{VaD}$ 에서 나타나는 의미 유창성의 저하가 $\mathrm{amMCI}$ 나 DAT와는 다 른 이유에서 비롯되었을 것임을 시사한다. $\mathrm{VaD}$ 환자의 경우 의미
유창성의 저하는 의미기억에 저장되어 있는 단어들 중에서 적절한 단어를 선택하여 인출하는 효율적인 찾기 전략의 장애로 인한 것 으로 설명되거나(Carew, Lamar, Cloud, Grossman, \& Libon, 1997; Chertkow \& Bub, 1990) 단어를 인출하는 능력의 장애로 인해 나타 나는 것으로 알려져 있다(Carew et al., 1997). 즉, 의미기억을 상실 하는 $\mathrm{DAT}$ 와는 달리, $\mathrm{VaD}$ 는 의미기억이 온전함에도 불구하고 이 러한 의미기억에 접근하지 못하거나 의미기억을 적절하게 인출하 지 못하여서 구어 유창성이 저하된다고 설명된다(Bonilla \& Johnson, 1995). 이러한 인출능력이나 효율적인 찾기 전략을 사용하는 능력은 전두엽의 기능과 관련되며(Carew et al., 1997), 이와 같은 전 두엽 기능의 저하는 혈관성 치매뿐만 아니라 그 전 단계인 $\mathrm{VaMCI}$ 에서도 이미 관찰되었다(Garrett et al., 2004). 따라서 DAT와는 달 리 초기가 아닌 후기 VaMCI 단계에서 조금 늦게 의미 유창성이 저 하되었으나 그 수준이 초기 $\mathrm{VaD}$ 까지 유지되고 더욱이 초기 $\mathrm{DAT}$ 의 의미 유창성 수준과도 차이가 없다는 사실은 후기 $\mathrm{VaMCI}$ 단계 에서 전두엽 기능의 중요한 퇴행이 발생할 가능성을 시사한다.

음소 유창성은 $\mathrm{amMCI}$ 의 경우에는 초기부터 정상집단과 차이 를 보였으나 E-amMCI의 수준이 $\mathrm{L}-\mathrm{amMCI}$ 와 초기 $\mathrm{AD}$ 까지 계속 유지되었다. 이 결과는 DAT 단계에 이르기 전 초기 $\mathrm{MCI}$ 단계에서 이미 음소 유창성의 저하가 시작되지만 치매(DAT) 초기에 이르기 까지 어느 정도 그 능력이 유지됨을 의미한다. 그러나 $\mathrm{VaMCI}$ 는 초 기부터 정상집단과 현저한 차이를 보였고 점차 빠른 속도로 저하되 어서 초기 $\mathrm{VaD}$ 는 초기 DAT보다 매우 저하된 수행을 나타냈다. 음 소 유창성 검사가 전두엽 기능을 평가하는 대표적인 검사로 인정받 고 있음(Lezak et al., 2012)을 감안할 때, $\mathrm{VaD}$ 와 DAT가 동일한 수 준의 치매심각도(CDR-GS 1.0)를 지녔음에도 불구하고 $\mathrm{VaD}$ 가 DAT보다 유의하게 낮은 수준의 음소 유창성을 나타낸 것은 동일 한 치매 수준에서 $\mathrm{VaD}$ 가 DAT에 비해 전두엽 기능이 더 저하되어 있다는 기존의 연구 결과들(Looi \& Sachdev, 1999; Reed et al., 2007) 을 지지한다. 또한, 초기 $\mathrm{amMCI}$ 의 음소 유창성이 정상집단보다 유 의하게 저하되고 그 수준이 초기 $\mathrm{AD}$ 까지 유지되었다는 본 연구의 결과는 $\mathrm{amMCI}$ 의 음소유창성이 초기에는 유지된다는 Jones 등 (2006)의 연구결과와는 상반되지만, 이제까지 알려진 바와는 달리 DAT가 초기 단계에서부터 미묘한 전두엽 기능의 손상을 보인다는 최근의 연구결과들(Baudic et al., 2006; Chen et al., 2000; van der Flier et al., 2002)과 맥락을 같이 하는 것으로 보인다.

본 연구의 의의는 $\mathrm{amMCI}$ 와 $\mathrm{VaMCI}$ 를 초기와 후기 단계로 세분 하여 정상집단, 초기 $\mathrm{MCI}$, 후기 $\mathrm{MCI}$ 및 초기 치매집단의 의미 유 창성과 음소 유창성의 저하 양상을 구체적으로 살펴보고, 선행연 구들에서 밝히지 못한 집단별 유창성의 저하 양상과 집단 간 차이 
를 발견하였다는 점이다. 본 연구의 결과를 요약하면, 기억성 경도 인지장애의 경우에는 $\mathrm{amMCI}$ 초기부터 $\mathrm{amMCI}$ 후기와 초기 $\mathrm{DAT}$ 에 이르기까지 의미 유창성이 점진적으로 계속 저하되었고, 음소 유창성은 $\mathrm{amMCI}$ 초기에 일단 저하된 후 그 수준이 초기 DAT까 지 유지되는 양상이 관찰되었다. 이와는 다르게 혈관성 경도인지장 애의 경우에는 $\mathrm{VaMCI}$ 후기가 되어야 의미 유창성이 저하되었으나 그 수준이 초기 $\mathrm{VaD}$ 까지 유지되는 양상을 보였고, 음소 유창성은 $\mathrm{VaMCI}$ 초기부터 저하되기 시작하여 초기 $\mathrm{VaD}$ 에 이르기까지 계 속해서 저하되는 양상을 보였다. 본 연구의 결과들은 $\mathrm{MCI}$ 종류 (amMCI vs. VaMCI)에 따라서 구어 유창성의 퇴행 양상이 다르다 는 사실을 보여주었을 뿐만 아니라 $\mathrm{MCI}$ 수준(초기 vs. 후기)에 따 라서도 구어 유창성의 수준이 다르다는 것을 보여 주었다. 이런 결 과로 미루어볼 때 선행연구들이 $\mathrm{MCI}$ 의 구어 유창성에 관하여 비 일관적인 결과들을 보고하게 된 이유는 연구대상으로 포함된 $\mathrm{MCI}$ 환자들의 수준이 서로 다르기 때문인 것으로 생각된다. 즉, 연구 대 상인 MCI의 CDR-GS가 모두 0.5라고 하여도, 초기 MCI(CDR-SB .5-2.0)와 후기 MCI(CDR-SB 2.5-4.0)가 포함된 비율에 따라서 다 른 결과가 도출되었을 것이다.

$\mathrm{amMCI}$ 와 VaMCI가 의미 유창성과 음소 유창성에 있어 각각 서 로 다른 퇴행 속도와 양상을 지니고 있음을 밝힌 본 연구의 결과는 임상장면에서 $\mathrm{MCI}$ 와 치매환자의 선별과 변별진단에 기초자료로 활용될 수 있을 것이다. 그러나 본 연구는 $\mathrm{MCI}$ 에서부터 치매에 이 르기까지 환자들의 변화를 추적 조사한 종단연구가 아니라 독립적 인 집단들의 수행을 비교한 횡단연구라는 점에서 제한점을 지닌다. 후속 종단 연구를 통해서 본 연구의 결과가 재검증되기를 기대한다.

\section{REFERENCES}

Adlam, A. L. R., Bozeat, S., Arnold, R., Watson, P., \& Hodges, J. R. (2006). Semantic knowledge in mild cognitive impairment and mild Alzheimer's disease. Cortex, 42, 675-684.

Alexopoulos, P., Grimmer, T., Perneczky, R., Domes, G., \& Kurz, A. (2006). Progression to dementia in clinical subtypes of mild cognitive impairment. Dementia and Geriatric Cognitive Disorders, 22, 27-34.

Baudic, S., Dalla Barba, G., Thibaudet, M. C., Smagghe, A., Remy, P., \& Traykov, L. (2006). Executive function deficits in early Alzheimer's disease and their relations with episodic memory. Archives of Clinical Neuropsychology, 21, 15-21.

Bonilla, J. L., \& Johnson, M. K. (1995). Semantic space in Alzheimer's disease patients. Neuropsychology, 9, 345-353.
Butters, N., Granholm, E., Salmon, D. P., Grant, I., \& Wolfe, J. (1987). Episodic and semantic memory: a comparison of amnesic and demented patients. Journal of Clinical and Experimental Neuropsychology, 9, 479-497.

Carew, T. G., Lamar, M., Cloud, B. S., Grossman, M., \& Libon, D. J. (1997). Impairment in category fluency in ischemic vascular dementia. Neuropsychology, 11, 400-412.

Chen, P., Ratcliff, G., Belle, S. H., Cauley, J. A., DeKosky, S. T., \& Ganguli, M. (2000). Cognitive tests that best discriminate between presymptomatic $\mathrm{AD}$ and those who remain nondemented. Neurology, 55, 1847-1853.

Chertkow, H., \& Bub, D. (1990). Semantic memory loss in dementia of Alzheimer's type. Brain, 113, 397-417.

Christensen, K. J., Multhaup, K. S., Nordstrom, S., \& Voss, K. (1991). A cognitive battery for dementia: development and measurement characteristics. Psychological Assessment: A Journal of Consulting and Clinical Psychology, 3, 168-174.

Cummings, J. L., Vinters, H. V., Cole, G. M., \& Khachaturian, Z. S. (1998). Alzheimer's disease: etiologies, pathophysiology, cognitive reserve, and treatment opportunities. Neurology, 51(1 Suppl 1), S2-S17.

Fahlander, K., Wahlin, Å., Almkvist, O., \& Bäckman, L. (2002). Cognitive functioning in Alzheimer's disease and vascular dementia: further evidence for similar patterns of deficits. Journal of Clinical and Experimental Neuropsychology, 24, 734-744.

Gainotti, G., Quaranta, D., Vita, M. G., \& Marra, C. (2014). Neuropsychological predictors of conversion from mild cognitive impairment to Alzheimer's disease. Journal of Alzheimer's Disease, 38, 481-495.

Garrett, K. D., Browndyke, J. N., Whelihan, W., Paul, R. H., DiCarlo, M., Moser, D. J., ... \& Ott, B. R. (2004). The neuropsychological profile of vascular cognitive impairment-no dementia: comparisons to patients at risk for cerebrovascular disease and vascular dementia. Archives of Clinical Neuropsychology, 19, 745-757.

Gorelick, P. B., Scuteri, A., Black, S. E., DeCarli, C., Greenberg, S. M., Iadecola, C., ... \& Petersen, R. C. (2011). Vascular contributions to cognitive impairment and dementia a statement for healthcare professionals from the American Heart Association/American Stroke Association. Stroke, 42, 26722713.

Hart, R. P., \& Best, A. M. (2014). Neuropsychological profile and performance variability in vascular cognitive impairment. International Journal of Clinical Medicine, 5, 1047-1058.

Heinzel, S., Metzger, F. G., Ehlis, A. C., Korell, R., Alboji, A., Haeussinger, F. B., ... \& Fallgatter, A. J. (2013). Aging-related cortical reorganization of 
verbal fluency processing: a functional near-infrared spectroscopy study. Neurobiology of Aging, 34, 439-450.

Henry, J. D., \& Crawford, J. R. (2004). A meta-analytic review of verbal fluency performance following focal cortical lesions. Neuropsychology, 18, 284-295.

Henry, J. D., MacLeod, M. S., Phillips, L. H., \& Crawford, J. R. (2004). A meta-analytic review of prospective memory and aging. Psychology and Aging, 19, 27-39.

Hsiung, G. Y. R., Donald, A., Grand, J., Black, S. E., Bouchard, R. W., Gauthier, S. G., ... \& Feldman, H. H. (2006). Outcomes of cognitively impaired not demented at 2 years in the Canadian Cohort Study of Cognitive Impairment and Related Dementias. Dementia and Geriatric Cognitive Disorders, 22, 413-420.

Jones, S., Laukka, E. J., \& Bäckman, L. (2006). Differential verbal fluency deficits in the preclinical stages of Alzheimer's disease and vascular dementia. Cortex, 42, 347-355.

Kang, Y. (2006). A normative study of the Korean-Mini Mental State Examination (K-MMSE) in the elderly. Korean Journal of Clinical Psychology, 25, $1-12$.

Kang, Y., Jang, S. M., \& Na, D. L (2012). Seoul Neuropsychological Screening Battery (2nd ed.). Seoul: Human Brain Research \& Consulting.

Keilp, J. G., Gorlyn, M., Alexander, G. E., Stern, Y., \& Prohovnik, I. (1999). Cerebral blood flow patterns underlying the differential impairment in category vs letter fluency in Alzheimer's disease. Neuropsychologia, 37, 12511261.

Kwon, O. D. (2012). Cognitive features of vascular dementia. Rijeka, Croatia: InTech-Open Access Publisher.

Lezak, M. D., Howieson, D. B., Bigler, E. D., \& Tranel, D. (2012). Neuropsychological assessment (5th ed.). New York, NY: Oxford University Press.

Looi, J. C., \& Sachdev, P. S. (1999). Differentiation of vascular dementia from AD on neuropsychological tests. Neurology, 53, 670-678.

Lucas, J. A., Ivnik, R. J., Smith, G. E., Bohac, D. L., Tangalos, E. G., Graff-Radford, N. R., ... \& Petersen, R. C. (1998). Mayo's older Americans normative studies: category fluency norms. Journal of Clinical and Experimental Neuropsychology, 20, 194-200.

McKhann, G., Drachman, D., Folstein, M., Katzman, R., Price, D., \& Stadlan, E. M. (1984). Clinical diagnosis of Alzheimer's disease Report of the NINCDS-ADRDA Work Group under the auspices of Department of Health and Human Services Task Force on Alzheimer's Disease. Neurology, 34, 939-944.
Murphy, K. J., Rich, J. B., \& Troyer, A. K. (2006). Verbal fluency patterns in amnestic mild cognitive impairment are characteristic of Alzheimer's type dementia. Journal of the International Neuropsychological Society, 12, 570574.

O’Bryant, S. E., Lacritz, L. H., Hall, J., Waring, S. C., Chan, W., Khodr, Z. G., ... \& Cullum, C. M. (2010). Validation of the new interpretive guidelines for the clinical dementia rating scale sum of boxes score in the national Alzheimer's coordinating center database. Archives of Neurology, 67, 746-749.

O'Bryant, S. E., Waring, S. C., Cullum, C. M., Hall, J., Lacritz, L., Massman, P. J., ... \& Doody, R. (2008). Staging dementia using Clinical Dementia Rating Scale Sum of Boxes scores: a Texas Alzheimer's research consortium study. Archives of Neurology, 65, 1091-1095.

Pakhomov, S. V., \& Hemmy, L. S. (2014). A computational linguistic measure of clustering behavior on semantic verbal fluency task predicts risk of future dementia in the Nun Study. Cortex, 55, 97-106.

Park, J. S., Kang, Y., Chang, E. J., Oh, E., Yu, K. H., \& Lee, B. C. (2006). Clustering and switching on verbal fluency in vascular dementia and dementia of the Alzheimer's type. Korean Journal of Communication Disorders, 11, 99-112.

Petersen, R. C. (2004). Mild cognitive impairment as a diagnostic entity. Journal of Internal Medicine, 256, 183-194.

Petersen, R. C., Doody, R., Kurz, A., Mohs, R. C., Morris, J. C., Rabins, P. V., ... \& Winblad, B. (2001). Current concepts in mild cognitive impairment. Archives of Neurology, 58, 1985-1992.

Petersen, R. C., Parisi, J. E., Dickson, D. W., Johnson, K. A., Knopman, D. S., Boeve, B. F., ... \& Braak, H. (2006). Neuropathologic features of amnestic mild cognitive impairment. Archives of Neurology, 63, 665-672.

Petersen, R. C., Smith, G. E., Waring, S. C., Ivnik, R. J., Tangalos, E. G., \& Kokmen, E. (1999). Mild cognitive impairment: clinical characterization and outcome. Archives of Neurology, 56, 303-308.

Reed, B. R., Mungas, D. M., Kramer, J. H., Ellis, W., Vinters, H. V., Zarow, C., ... \& Chui, H. C. (2007). Profiles of neuropsychological impairment in autopsy-defined Alzheimer's disease and cerebrovascular disease. Brain, 130, 731-739.

Román, G. C., Tatemichi, T. K., Erkinjuntti, T., Cummings, J. L., Masdeu, J. C., Garcia, J. A., ... \& Moody, D. M. (1993). Vascular dementia: diagnostic criteria for research studies: report of the NINDS-AIREN International Workshop. Neurology, 43, 250-260.

Sauzéon, H., Lestage, P., Raboutet, C., N’Kaoua, B., \& Claverie, B. (2004). Verbal fluency output in children aged 7-16 as a function of the production 
criterion: qualitative analysis of clustering, switching processes, and semantic network exploitation. Brain and Language, 89, 192-202.

Solomon, P. R., Hirschoff, A., Kelly, B., Relin, M., Brush, M., DeVeaux, R. D., ... \& Pendlebury, W. W. (1998). A 7 minute neurocognitive screening battery highly sensitive to Alzheimer's disease. Archives of Neurology, 55, 349355.

Tham, W., Auchus, A. P., Thong, M., Goh, M. L., Chang, H. M., Wong, M. C., ... \& Chen, C. P. H. (2002). Progression of cognitive impairment after stroke: one year results from a longitudinal study of Singaporean stroke patients. Journal of the Neurological Sciences, 203, 49-52.

Van Der Flier, W. M., Van Den Heuvel, D. M. J., Weverling-Rijnsburger, A. W. E., Spilt, A., Bollen, E. L. E. M., Westendorp, R. G. J., ... \& Van Buchem, M. A. (2002). Cognitive decline in $\mathrm{AD}$ and mild cognitive impairment is associated with global brain damage. Neurology, 59, 874-879.

Wentzel, C., Rockwood, K., MacKnight, C., Hachinski, V., Hogan, D. B., Feldman, H., ... \& McDowell, I. (2001). Progression of impairment in patients with vascular cognitive impairment without dementia. Neurology, 57, 714716. 


\section{국문초록}

\section{기억성 경도인지장애와 혈관성 경도인지장애의 구어 유창성 저하 양상 비교}

김해윤 ${ }^{1} \cdot$ 강연욱 ${ }^{12} \cdot$ 유경호 ${ }^{2} \cdot$ 이병철2

'한림대학교 심리학과, ${ }^{2}$ 한림대학교성심병원 신경과

배경 및 목적: 본 연구는 구어 유창성이 기억성 경도인지장애(amMCI)와 혈관성 경도인지장애(VaMCI)에서 어떻게 저하되는지를 밝 히고 그 저하 양상이 의미 유창성과 음소 유창성에 있어 차이가 있는지를 알아보고자 수행되었다. 방법: 정상노인 34명, amMCI 72명, VaMCI 70명, 알츠하이머형 치매(DAT) 36명 및 혈관치매 $(\mathrm{VaD}) 39$ 명이 연구에 참여하였다. 경도인지장애집단들은 CDR-SB점수 2.0 을 기준으로 초기(E)와 후기 $(\mathrm{L})$ 로 다시 분류되었고, 모든 연구대상자들에게 의미 유창성(동물) 검사와 음소 유창성(ㄱ, O , ㅅ) 검사를 실 시하였다. 결과: 의미 유창성은 amMCI의 경우에는 초기부터 DAT까지 점진적으로 계속 저하된 반면, VaMCI의 경우에는 초기에는 유지되다가 후기에 저하되어 $\mathrm{VaD}$ 까지 유지되는 양상을 보였다. 음소 유창성은 $\mathrm{amMCI}$ 의 경우에는 초기에 저하되어 $\mathrm{DAT}$ 까지 유지되 었고, $\mathrm{VaMCI}$ 의 경우에는 초기부터 $\mathrm{VaD}$ 까지 점진적으로 계속 저하되는 양상을 보였다. 논의 및 결론: 연구 결과는 $\mathrm{amMCI}$ 와 $\mathrm{VaMCI}$ 가 의미 유창성과음소 유창성에 있어 각각 서로 다른 퇴행 속도와 양상을 지니고 있음을 시사한다.

핵심어: 구어 유창성, 의미 유창성, 음소 유창성, 경도인지장애, 기억성 경도인지장애, 혈관성 경도인지장애

본 연구는 한림대학교 특성화사업 연구비(HRF-S-21)의 지원에 의한 연구임.

\section{참고문헌}

강연욱(2006). K-MMSE(Korean-Mini Mental State Examination)의 노인 규준 연구. 한국심리학회지: 일반, 25, 1-12.

강연욱, 장승민, 나덕렬(2012). 서울신경심리검사 2판. 서울: 휴브알엔씨.

박재설, 강연욱, 장은주, 오은아, 유경호, 이병철(2006). 혈관성 치매와 알츠하이머형 치매의 단어 유창성 비교: 군집화와 전환. 언어청각장애연구, 11, 99-112. 